\title{
LAMLEC: a dimensão lúdica no Ensino de Ciências
}

\section{LAMLEC: the ludical dimension on the teaching of sciences}

\author{
${ }^{1}$ Anderson Domingues Côrrea \\ ${ }^{1}$ Valéria Vieira valvibr@yahoo.com.br \\ ${ }^{1}$ Verônica Pimenta Velloso
}

\section{RESUMO}

O artigo tem por fim apresentar uma análise reflexiva sobre o LAMLEC - Laboratório de Materiais Lúdicos para o Ensino de Ciências, cuja trajetória está vinculada a do próprio Instituto Federal de Educação, Ciência e Tecnologia do Rio de Janeiro, onde está sediado. Paralelamente, essa apresentação será articulada a elucidação dos objetivos do laboratório, divulgação das propostas mais recentes para a educação e ensino de ciências, relacionando com as metodologias utilizadas na elaboração e validação dos seus materiais,incluindo aexibição dealguns de seus produtos. O propósito na divulgação de seus materiais e metodologias é de suprir uma carência já observada no ensino de ciências que necessita acompanhar as inovações científicas e tecnológicas presentes no cotidiano do jovem aprendiz. A partir desse objetivo os autores relatam a experiência de unir a divulgação científica à presença do lúdico na construção de materiais, partindo de uma equipe bem diversificada para isso, além de produtos dissemináveis do LAMLEC que podem ser trabalhados na educação formal e não formal, como jogos, histórias em quadrinhos e músicas.Trata-se de uma pesquisa aplicada com abordagem qualitativa, de natureza observacional descritiva.

Palavras-chave: ensino de ciências; metodologias de ensino; divulgação científica.

\begin{abstract}
He articleaimstopresent a reflectiveanalysisof LAMLEC - Laboratório de Materiais Lúdicos para o Ensino de Ciências, whosehistoryislinkedtotheown Instituto Federal de Educação, Ciência e Tecnologia do Rio de Janeiro, where it ishosted. At the same time, this presentation will articulate the elucidation of the lab's objectives, dissemination of the most recent proposals for education and science education, relating to methodologies used in the preparation and validation of their materials, including display of some of its products. The purpose in disseminating their materials and methodologies is to supply a shortage already seen in science education that needs follow scientific and technological innovations present in the young apprentice everyday. With this purpose, the authors report their experience to combine science communication to the ludic presence in building materials, starting from a well diversified staff for this, further LAMLEC's spread products that can be worked in formal and non-formal education, such as games, comics and music.
\end{abstract}

Keywords: science education; teaching methodologies; scientific dissemination.

1 Instituto Federal de Educação, Ciência e Tecnologia do Rio de Janeiro (IFRJ). 


\section{INTRODUÇÃO}

\section{Música LAMLEC}

Arte e ciência estão em toda parte

Seu elo é forte, nunca se reparte

Criatividade, inspiração pro trabalho de artista

São igualmente essenciais para função do cientista

Estar atento aos detalhes

Que os outros não veem faz parte do ofício

Faz parte do ofício

Este talento é muito útil

Apesar de ser difícil, apesar de ser difícil

Materiais lúdicos tem processo de produção

Similar aos laboratórios de alquimia

Da antiga geração

Ôôôôô, LAMLEC é ciência, arte, educação

$E$ um leque de opções essenciais

Para a divulgação de seus materiais

\section{LAMLEC}

O lúdico desperta a curiosidade

Dos alunos de qualquer idade

Pois, ao mesmo tempo que se divertem

Eles aprendem conteúdo de verdade

A ludicidade do ensino

${ }^{1}$ (Música tema do LAMLEC)
Ajuda a concentração na atividade

Dinamiza transforma e educa

O processo de aprendizagem

ôôôôô, LAMLEC é ciência, arte, educação

$E$ um leque de opções essenciais

Para a divulgação de seus materiais

LAMLEC

Justamente nesse momento

Há vários materiais em desenvolvimento

Vídeos, jogos, literatura

Músicas, site e experimentos

À aprendizagem significativa

Promovemos favorecimento

Identificamos o conhecimento prévio

De todos os elementos

Ôôôôô, LAMLEC é ciência, arte, educação

E um leque de opções essenciais

Para a divulgação de seus materiais

LAMLEC

O Laboratório de Materiais Lúdicos para o Ensino de Ciências (LAMLEC), espaço situado atualmente no Instituto Federal de Educação, Ciência e Tecnologia do Rio de Janeiro - IFRJ, em Nilópolis, reúne professores e alunos vinculados aos diversos cursos da instituição, com fins de realizar estudos e ações voltadas para a criação de materiais didáticos que despertem curiosidade e interesse no processo de ensino e aprendizagem de ciências na educação básica e superior. A sua criação no ano de 2007, no então, denominado Centro Federal de Educação Tecnológica de Química de Nilópolis, fez parte da preparação para a criação de um mestrado profissional, o Mestrado Profissional em Ensino de Ciências e Matemática (2008), sendo denominado atualmente, Mestrado Profissional em Ensino de Ciências. Com a criação, em 2014, do Mestrado Acadêmico em Ensino de Ciências, ampliam-se os cursos oferecidos de Pós-Graduação em Ensino de Ciências, no IFRJ - Nilópolis, e, consequentemente, aumentam os integrantes do LAMLEC.

Em 2007, o LAMLEC foi contemplado com recursos da FAPERJ no projeto "Diagnóstico e intervenção do uso racional de medicamentos em uma população de adolescentes: uma questão de promoção da saúde”, quando foram adquiridos os equipamentos iniciais necessários para a produção dos materiais lúdicos para o ensino. Desde então, configura-se uma tendência a projetos voltados para um dos temas transversais propostos nos Parâmetros Curriculares Nacionais - a saúde (BRASIL, 1997). O surgimento desse espaço sinaliza assim, para ações que podem viabilizar diálogos mais descontraídos entre alunos e professores e diversas disciplinas, trazendo contribuições para a renovação do ensino de ciências.

1 Música e letra confeccionadas pelos integrantes do LAMLEC, que descrevem os princípios do Laboratório. ANDERSON DOMINGUES CORRÊA e EDSON RODRIGUES, em 2014. 


\section{1 O LAMLEC e sua história}

A história do Laboratório, assim como a dos Mestrados em Ensino de Ciências e a da própria instituição em que estão inseridos - o IFRJ, está diretamente ligada ao processo de institucionalização do ensino da química no Rio de Janeiro. Fazendo uma retrospectiva, o IFRJ foi criado mediante a transformação do CEFET de Química de Nilópolis (Lei 11.892, de 29/12/2008, artigo 5º inciso XXVI) e este, por sua vez, veio dar prosseguimento à Escola Técnica Federal de Química, criada no então Distrito Federal em 1942, quando a formação profissional passou a ser de nível secundário. Configura-se então, uma história institucional da ciência da química e do ensino técnico-profissional entrelaçada com o tema em questão.

Antes dos anos de 1940, as iniciativas governamentais tomadas no país com relação ao ensino técnico profissional restringiram-se ao ensino de ofícios e aprendizagem agrícola de nível primário, gratuito, assumindo um tom assistencialista, sendo voltado para os setores mais desfavorecidos da população. Neste quadro, as medidas tomadas pelo governo Nilo Peçanha destacaram-se, inicialmente no estado do Rio de Janeiro, com a criação de quatro escolas profissionais em 1906 e, posteriormente como Presidente da República, em substituição a

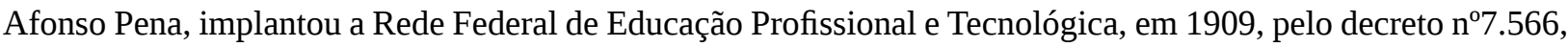
de 23 de setembro. Nesta ocasião, foram criadas dezenove escolas de Aprendizes e Artífices pelo país, vinculadas ao Ministério dos Negócios da Agricultura, Indústria e Comércio, criado nesse mesmo ano (BRASIL, 2009).

Embora a educação tenha sido tratada como questão nacional no governo de Getúlio Vargas (1930-1945), as reformas educacionais empreendidas em 1931 por Francisco Campos, como Ministro da Educação e Saúde, foram de tom centralizador e elitista. Em contrapartida, os educadores que assinaram o Manifesto dos Pioneiros da Educação Nova (1932), entre os quais Anísio Teixeira, Fernando Azevedo, defendiam uma educação voltada para todos, representativa de uma democracia liberal (FAVERO, 2006). Essas tensões políticas vivenciadas às vésperas da Constituição de 1937, que impôs um regime autoritário, acompanharam o posicionamento do governo brasileiro com relação à segunda guerra mundial, impedindo nesse sentido o funcionamento de instituições de ensino de cunho democrático e reforçando a dicotomia entre a formação profissional e a formação acadêmica que envolveu a história do ensino técnico industrial no Brasil. Neste quadro, o ensino da química, presente em cursos técnicos e industriais de nível secundário e na Escola Nacional de Química, passaram por sucessivas mudanças de ordem estrutural. Pelo decreto 452, de 05/07/1937, que criou a Universidade do Brasil, a Escola Nacional de Química passou a ser uma de suas unidades, além de um Instituto de Química e Eletroquímica, que teria por fim cooperar com os trabalhos dos estabelecimentos de ensino. Depois da extinção da Universidade do Distrito Federal, cuja criação em 1935 coube aos partidários de uma educação democrática, as suas faculdades de Filosofia e Letras; de Ciências; de Política e Economia; e os cursos vindos da Faculdade de Educação foram incorporados à Faculdade Nacional de Filosofia, Ciências e Letras da Universidade do Brasil, pelo decreto nº 1063, de 30/01/1939.

Foi nesse contexto do governo Vargas, que elegeu a educação e o trabalho como temas da "salvação nacional” a serviço da modernização e do processo de industrialização como políticas de Estado (CIAVATTA, 2009), que se criou no Distrito Federal a Escola Técnica de Química, com fins de ministrar o curso de química industrial, integrando a rede federal do ensino industrial (art. $2^{\circ}$ do decreto ${ }^{\circ}$ 4.127, de 25/02/1942). Embora, este tenha passado a ser de nível secundário, ele nasce no bojo da Reforma do Ministro da Educação e Saúde Gustavo Capanema, que mantém uma postura considerada elitista com respeito ao ensino técnico-industrial, dificultando o ingresso de setores mais pobres no ensino superior (PICANÇO, 1995). É interessante observar que a partir dos anos de 1950, com o novo surto industrial a nível mundial, pós $2^{a}$ guerra, que se estendeu até a década de 1970, conhecida como a era desenvolvimentista (HOBSBAWN, 1995), o ensino técnico e profissional voltou a ser objeto de atenção maior dos governos. No governo de Juscelino Kubitschek, com o boom da indústria automobilística e seu Plano de Metas para o país, de cinquenta anos em cinco, aquelas escolas técnicas e industriais, como a de química, tornaram-se autarquias, conquistando autonomia didática e de gestão, sendo transformadas em Escolas Técnicas Federais em 1959. Já durante o governo militar, a Lei de Diretrizes e Base 5692, de 11/08/1971, torna compulsório o ensino técnico-profissional, estabelecendo a iniciação do trabalho e aptidões no $1^{\circ}$ grau e qualificação profissional no segundo grau. Esta lei é revogada pela Lei de Diretrizes e Bases para a Educação Nacional 9.394, de 20/12/1996, que 
propôs entre outras mudanças uma gestão democrática do ensino público e a vinculação entre educação escolar, o mundo do trabalho e as práticas sociais. Há então, a proposta de uma educação profissional que favorece a inclusão social e a democratização. Mas já no ano seguinte, é extinto o ensino médio integrado, que reunia o médio regular e o técnico, sendo recriada a dicotomia entre o profissional e o acadêmico (ZIBAS, 2006).

Entre idas e vindas, no período de 1946 a 1986, a Escola Técnica de Química, que em 1959 passou a Escola Técnica Federal de Química do Distrito Federal, e que a partir de 1965, devido a transferência do Distrito Federal para Brasília, foi denominada de Escola Técnica Federal de Química do Estado da Guanabara, e depois da fusão do estado do Rio de Janeiro e da Guanabara, Escola Técnica Federal de Química do Rio de Janeiro, funcionou precariamente nas dependências da Escola Técnica Federal Celso Suckow da Fonseca, depois Centro Federal de Educação Tecnológica Celso Suckow (Lei nº45, de 30/06/1978). Já na década de 1980, com o surgimento de novas tecnologias, inicia-se um processo de incorporação dessas pelas instituições de ensino técnico federal, o que se expressou na aparelhagem e melhoria de suas instalações e na nova designação de centros federais de educação tecnológica. A partir de 1981, a então Escola Técnica Federal de Química do Rio de Janeiro (ETFQ-RJ), funcionando ainda nas dependências do CEFET Celso Suckow, até então somente com o curso Técnico em Química, cria seu segundo curso, o Curso Técnico em Alimentos. Em 1988, já instalada no bairro do Maracanã em sua sede própria desde 1985, criou o Curso Técnico em Biotecnologia, ambos de nível médio. Em 1994, consegue expandir-se com mais uma unidade instalada no município de Nilópolis, situado na Baixada Fluminense. Com a transferência de sua sede para Nilópolis, tornou-se - Centro Federal de Educação Tecnológica de Química de Nilópolis/RJ, o que permitiu a oferta de curso superior e de pós-graduação lato-sensu e stricto-sensu.

Em 2003, na unidade de Nilópolis, buscando atender à região da Baixada Fluminense no sentido de valorizar as suas tradições culturais manifestas, criou-se o Curso Superior de Tecnologia em Produção Cultural, abrindo novas possibilidades de trabalho e profissão na área da cultura. No ano seguinte, foram criadas as licenciaturas de química e física, além do Curso Superior de Tecnologia em Produtos Naturais, hoje Bacharelado em Química. O Curso de Gestão de Produção em 2006, e, posteriormente, no ano de 2007, a licenciatura em matemática. Os objetivos na criação desses cursos eram de suprir a carência de professores nessas áreas, e, também, desenvolver pesquisas e capacitar pessoal para trabalhar na indústria.

Em 2008, pela Lei 11.892 de 29 de dezembro, é instituída a Rede Federal de Educação Profissional, Científica e Tecnológica, com a criação dos Institutos Federais de Educação, Ciência e Tecnologia, que reúnem numa mesma instituição a educação superior, básica e profissional.

Diante desse quadro, percebemos os significados e abrangências diversas da educação destinada ao ensino técnico, industrial e profissional entre os séculos XX e XXI em nosso país, que nunca deixou de estar relacionada às conjunturas sociais, políticas e econômicas, a nível local e global. Algumas mudanças se evidenciam no trajeto irregular dessas modalidades de ensino reprodutoras de hierarquias sociais relacionadas especificamente à química, mas que não deixam de estar ligadas a outras ciências, naturais e humanas, assim como à própria cultura.

Em 2007, nasce o LAMLEC na unidade de Nilópolis, do então CEFET Química, com a proposta de criar um novo espaço que se diferencia da sala de aula, reunindo alunos de vários cursos e favorecendo a relação entre eles e possíveis trocas, na elaboração de materiais didáticos para a educação básica.

A criação de um espaço diferenciado voltado para a melhoria do processo ensino-aprendizagem e para o conhecimento de uma educação científica, favorece a intercessão entre o pensar e o fazer, o aprendizado da teoria e a construção de produtos e técnicas, aproximando-se, de certa forma das ações da década de 1980, no Brasil. Ações estas que criaram espaços não formais de educação com fins de promover a divulgação científica, voltados a um público mais abrangente (museus e centros culturais de ciências). O LAMLEC traz assim, a marca do CEFET Química, que desenvolveu várias atividades durante a década de 1990 na região da Baixada Fluminense, procurando articular a ciência à arte e à cultura, dando vazão ao discurso da divulgação científica que compreende a ciência como cultura (ARAÚJO-JORGE, 2004). 


\section{2 Uma missão: $O$ aperfeiçoamento do Ensino de Ciências por meio de uma parceria entre o Lúdico e a Divulgação Científica}

O surgimento do LAMLEC no início do século XXI corrobora com o que é referenciado por diversos autores como umaépoca onde mudanças para o Ensino de Ciências são necessárias eurgentes (CACHAPUZ et al., 2005; KRASILCHIK, 2004; DELIZOICOV, 2002). Esse pensamento é alicerçado por acontecimentos que aparecem desde meados do século anterior, podendo ser exemplificado pelo advento das tecnologias, descobertas nas pesquisas científicas, ou mesmo uma insatisfação constante do professor e do aluno com as metodologias utilizadas no ensino.

Neste período de consolidação do pensamento sobre renovação do ensino, autores consagrados nacional e internacionalmente, despontam com novas propostas e modelos, como ideias para concretizar mudanças no Paradigma Educacional vigente, visto que o mesmo já não atendia as demandas. Para o Paradigma Educacional vigente a visão conservadora e mecanicista da Educação era o próprio reflexo do que se pensava sobre as Ciências, as somas das partes seriam iguais ao todo (BOAVENTURA, 1987). Nesta visão, soma-se a necessidade de que os conteúdos curriculares fossem fragmentados cada vez em partes menores, surgindo a disciplinarização e, consequente, superespecialização da matriz curricular inserida em áreas do conhecimento, tudo isso com a justificativa de facilitar o aprendizado, mesmo que a superespecialização descontextualizasse o mesmo.

Pensadores que buscassem novas propostas precisariam ir na contramão dessas colocações, com "autonomia e criticidade”, parafraseando aqui Paulo Freire que ressalta a importância do pensamento crítico no ensino(FREIRE, 1996). Nesse contexto, é de extrema importância que a formação dos profissionais, pensadores que atuam diretamente no ensino, seja ela inicial ou continuada, atenda a todas essas demandas. Para isso muitos estudiosos ressaltam a acuidade de ações como o aprendizado constante do professor (CARVALHO e GILPÉREZ, 2011), uma aproximação do conteúdo trabalhado em sala de aula com o cotidiano do aluno, no Brasil muito bem representado pelas obras de Paulo Freire, e, uma valorização na escola das experiências que o aluno traz de sua vida extraescolar (BRASIL, 1996), e seus conhecimentos prévios (AUSUBEL et al., 1978). No âmbito internacional, Perrenoud (1999) aponta para uma transformação da avaliação, substituindo a noção de que uma boa avaliação é realizada por medição, mostrando, desta forma, a necessidade de formação do indivíduo. A UNESCO (1999) marca presença na introdução desses conceitos publicando um documento que enfatiza os Quatro Pilares da Educação, escrito por Jacques Delors, também voltado a ações como aprender a conhecer, aprender afazer, aprender a viver com os outros e aprender a ser.

Todos esses esforços e a introdução de novos pensamentos provocariam uma discussão e proposição de uma mudança no conceito de Educação. Abre-se espaço para a criação de um novo paradigma, o Paradigma Educacional Emergente, holístico, em formato de teia de conhecimentos (MORIN, 2000). A visão mecanicista começa a ser substituída pela física quântica, onde tudo estaria ligado, e, atualmente, conectado. Inicia-se a discussão de multi, inter e transdiciplinaridade. Autores como Japiassu e Fazenda conceituaram esses termos, no entanto, também, apontaram a dificuldade de um trabalho real com eles na educação (JAPIASSÚ, 1976; FAZENDA, 2011).

A importância desses novos conceitos é de poder introduzi-los no ensino, de forma coerente, sendo necessário para isso uma boa formação por parte do mediador. Para se obter essa boa formação é necessário muito estudo, só com conhecimento real é possível se trabalhar de forma correta, prazerosa, e, principalmente acessível ao aprendiz. Desde a criação do LAMLEC buscou-se pensar nesses conceitos e em trabalhá-los no processo ensino-aprendizagem, com novas ferramentas, novos meios de estimular o aluno. Este, muitas vezes, busca sozinho o conhecimento pela educação informal, já que vive na era do conectado, da internet presente nas plataformas mais próximas como tabletes e celulares. Nessa conjectura, é ainda mais necessário que a educação formal dê conta desse processo de aprendizagem, que ela se proponha a conhecer essas necessidades dos alunos, e se conecte junto a esse aprendiz, nascido na era da tecnologia. 
Alguns autores na tentativa de compreender os significados e a presença dos diferentes tipos de educação na vida do aluno, propõem definições para educação (COLLEY et al., 2002; GOHM,1999). Partem do princípio que educação aquela que é adquirida ao longo da vidado indivíduo, e pode ser dividida em três segmentos: educação escolar formal desenvolvida nas escolas; educação não-formal, que ocorre quando existe a intenção de determinados sujeitos em criar ou buscar determinados objetivos fora da instituição escolar, e , a educação informal, transmitida pelos pais, no convívio com amigos, cinemas, teatros, leituras, ou seja, aquela que decorre de processos naturais e espontâneos, atualmente também muito associada à internet.

Pensando no processo de criação do LAMLEC e sua filosofia, percebe-se que ele está inserido dentro de um espaço formal de ensino, o IFRJ, e compartilha com diferentes instituições de ensino seus produtos didáticos, dissemináveis, no entanto, busca trabalhar, também, a educação não formal. Os alunos do laboratório são estimulados pelos professores responsáveis e/ou orientadores a trabalharem com materiais lúdicos e novas metodologias de ensino, direcionados, mas sem uma educação formal, assim, ocorre para esses monitores do LAMLEC a educação não formal. Os trabalhos desses alunos em grupos de pesquisa acontecem muitas vezes de forma autônoma, eles se sujeitam a aquisição de novas informações e construção de novos conhecimentos, compartilham com o grupo esse conhecimento nas reuniões e no convívio do laboratório, estão sempre conectados, utilizam a internet quase sempre como fonte de pesquisa, se comunicam em redes sociais, e, criam apresentações e dinâmicas para expor ao grupo e aos professores toda essa construção do conhecimento.

De acordo com Libâneo (2005), o poder pedagógico de vários agentes educativos, formais e não formais vêm se acentuando. Ocorrem ações pedagógicas nos meios de comunicação, nos movimentos sociais e grupos humanos, como pode ser exemplificado no caso do laboratório apresentado. Além disso, para o mesmo autor, essa intervenção também pode estar presente na criação dos materiais didáticos. Pensando nisso, os integrantes do LAMLEC vislumbram que seus produtos sejam plausíveis de serem trabalhados na educação formal, por meio de mediações e intervenções dos professores. A exemplo de um produto, pode-se citar o site do laboratório, que exemplifica a definição de produto disseminável, um meio de divulgação de tudo o que é produzido, já que a internet é um veículo de transmissão de informações, vindo assim a corroborar com a divulgação científica. Para a internet cabe muitas vezes o papel de comunicar a ciência além do espaço formal da educação, além da experiência adquirida pelo indivíduo no espaço escolar, ao público geral. A ciência, por sua própria natureza, tem de ser aberta e comunicada a todos, não apenas à comunidade científica (SILVEIRA, 2009).

Esse papel de comunicação da ciência por diversos meios é conferido à divulgação científica, ela tem como objeto de estudo a melhor maneira de proporcionar o conhecimento de fatos científicos e/ou a compreensão da ciência à toda população. Como exemplo, cita-se Martins et al. (2004), que postula que a divulgação científica realizada em materiais didáticos como textos científicos também pode ter a função de motivar ou estruturar a aula, podendo desenfrear debates para novas práticas de leitura, estabelecer relações com o cotidiano do aluno, entre outros.

De acordo com Pinto (2007), os textos de divulgação científica promovem um ensino comprometido para além da transmissão de conceitos, mas, também, para a divulgação de padrões de fazer ciência. A divulgação científica no processo ensino-aprendizagem de ciências tem sido apontada como recurso educativo importante, e, com potencial para a criação de estratégias discursivas, educativas e mediadoras de uma aprendizagem significativa.

Desta forma, uma das vertentes do laboratório, é associar a divulgação científica, à ludicidade, com ênfase na utilização de novos materiais e metodologias voltadas ao aprimoramento do ensino de ciências, pode ser um desafio aos seus membros, pesquisadores e divulgadores, mas provavelmente se alcançado proporcionará um aumento e propagação do lúdico, rompendo barreiras físicas e geográficas.

A compreensão da ludicidade vem desde a etimologia da palavra lúdico (originária do latim, ludus significa brincar),até suas ações nas quais podem-se incluir jogos, brincadeiras e divertimentos, sendo assim passiveis de ocorrer uma aprendizagem significativa e motivacional. De acordo com Friedman (1996, apud SOUSA, 
2012) para proporcionar ao aprendiz a aprendizagem significativa deve ser oferecido uma quantidade diversificada de tarefas, e, para isso, o professor deve conhecer muitas técnicas, recursos, metodologias diferenciadas.

Assim, o lúdico voltado ao processo ensino-aprendizagem, representado por diferentes formas, deve ser considerado como um promotor da aprendizagem na educação formal, não-formal ou informal, possibilitando a aproximação das pessoas ao conhecimento científico. Pensando na educação formal, trabalhar com ludicidade se constitui um importante recurso para o professor desenvolver a habilidade de resolução de problemas, favorecer a apropriação de conceitos e atender aos anseios daqueles que ainda estão em processo de desenvolvimento (CAMPOS, 2008 apud SOUSA, 2012).Pesquisas que enfatizam o lúdico a partir de estratégias metodológicas, apontam contribuições significativas no processo ensino-aprendizagem (SOUSA, 2012; CRUZ, 2013).

Cruz (2013) ressalta a importância de conferir ao lúdico, seriedade para atuar no desenvolvimento cognitivo do sujeito durante o processo de aprendizagem. Para a autora o lúdico estimula a curiosidade, aguça a concentração e a atenção, e, auxilia no desenvolvimento cognitivo. A estimulação da estrutura cognitiva do aprendiz diz respeito à assimilação de conceitos, e, consequente superação da aprendizagem mecânica, proporcionando um significado desses conceitos ao aluno, auxiliando na resolução de situações-problemas. Essa assimilação de um novo conceito para aplicá-lo na resolução dos problemas, faz com que o aluno construa a sua própria interpretação, auxiliando-o em sua vida cotidiana, por meio de uma reflexão crítica da realidade em que vive.

No âmbito do ensino formal, o trabalho com a atividade lúdica necessita, primeiramente, de uma apropriação dos conteúdos, deixando claro ao aprendiz que a diversão e a brincadeira não são um passatempo, mas uma associação do prazer com a finalidade de desenvolvimento do pensamento lógico e da criticidade.

Assim, pode-se dizer que esses conteúdos apresentados de forma lúdica são mais propícios a serem incorporáveis à estrutura cognitiva do aprendiz, proporcionando um significado, e, de acordo com a teoria de Ausubel et al. (1978), a ocorrência da aprendizagem significativa. Para estes autores o material a ser aprendido precisa ser potencialmente significativo, além disso, o aprendiz precisa manifestar uma disposição para relacioná-lo aos seus conhecimentos prévios produzindo um novo conhecimento. Um conteúdo que é exposto de forma lúdica e prazerosa, interativa e contextualizada com o cotidiano do aprendiz facilitará a construção de novos conhecimentos.

\section{PROCESSO DE CRIAÇÃO DOS MATERIAIS: CAMINHO EXPERIMENTAL}

... O fator isolado mais importante influenciando a aprendizagem é aquilo que o aluno já sabe; determine isso e ensine-o de acordo. (AUSUBEL apud Moreira, 1999, p. 163).

A criação dos materiais do LAMLEC possui um percurso metodológico que se baseia na aprendizagem significativa. Inicialmente observou-se as percepções e os conhecimentos prévios dos aprendizes em relação ao assunto a ser abordado e sobre o material lúdico a ser elaborado. Criou-se um material levando em consideração o que foi observado, com o intuito de aproximar o aluno do assunto e motivá-lo a se envolver no seu próprio aprendizado de forma ativa. A aplicação desse material lúdico, funciona como um organizador prévio e como um instrumento de interação e prazer, para que desta forma, o aprendiz tenha interesse em se aprofundar no assunto. Ao final, são analisados as percepções e aprendizados construídos. Para melhor organizar o texto dividiu-se os tópicos em pré-produção, produção e pós-produção.

\section{1 Pré-produção}

Antes da produção dos materiais faz-se a escolha de um tema e verifica-se o conhecimento prévio e as dificuldades que o público alvo apresenta em relação ao tema escolhido. Essas informações servirão para a escolha da forma as quais os conteúdos serão apresentados nos materiais. 
Os subsunçores (conhecimentos prévios) precisam ser identificados pelo professor, para que desta forma possam servir de base para a formulação de novos conceitos por parte do aprendiz. Uma vez tendo identificado esses conhecimentos prévios o professor será capaz de promover a ancoragem dos dois saberes, facilitando a aprendizagem significativa. Desta forma, qualquer indivíduo se torna capaz de compreender a ciência, pois ela está repleta de âncoras, ou seja, conceitos aplicáveis ao nosso cotidiano.

Após essa etapa, realiza-se uma pesquisa entre os alunos para identificar quais são os materiais que eles mais se interessam, assim serão escolhidos os materiais aos quais os aprendizes mostraram os maiores graus de interesse ou satisfação.

O próximo passo após a escolha do tema e do material lúdico é fazer um levantamento bibliográfico sobre os conteúdos a serem apresentados, listar os tópicos principais e finalmente elaborar o conteúdo a figurar no material.

\section{2 Produção}

Para facilitar este processo de aprendizagem ‘Organizadores Prévios’, conteúdos introdutórios, devem ser utilizados, pois servem de pontes cognitivas entre o que o aluno já sabe e o que ele deve aprender. Desta forma o conteúdo pode ser realmente aprendido de forma significativa.

O aprendizado significativo acontece quando uma informação nova é adquirida mediante um esforço deliberado por parte do aprendiz em ligar a informação nova com conceitos e proposições relevantes em sua estrutura. (AUSUBEL, 1978, p. 159).

Da mesma forma que se realiza um levantamento bibliográfico, deve-se realizar um levantamento dos materiais (jogos, histórias em quadrinhos, músicas e outros) que os alunos usam cotidianamente para se divertirem. Usar, experimentar e testar esses materiais objetivando construir um material lúdico atrativo, ou seja, semelhante aos materiais que o público alvo está acostumado a brincar.

Para iniciar a confecção de um protótipo do material é necessário realizar um pré-teste com um grupo reduzido de pessoas com o mesmo perfil (sócio, econômico, cultural e faixa etária) do grupo a que se destina este material educativo. As próximas ações serão observar a utilização do material e realizar entrevistas para saber sobre o entendimento dos conceitos e termos utilizados, além de verificar o interesse pelo material, apontando os pontos positivos e negativos. Posteriormente, realizar os ajustes necessários e aplicar um novo pré-teste para novos ajustes, se este for o caso.

\section{3 Pós-produção}

A pós-produção é o momento em que o material didático está pronto para ser utilizado no ensino, para isso é preciso indicar como o docente pode trabalhar com esta nova ferramenta. Assim, não com o intuito de fornecer uma receita, pois tudo o que é construído pode ser usado da forma que for necessária ou mais atraente, mas, com a finalidade de direcionar aqueles que precisam de uma dica de como usar o produto disseminável, sugere-se a divisão desta etapa em dois momentos com diferentes possibilidades, são eles a metodologia de ensino, e, a coleta e análise de dados. A primeira delas a ser apresentada, com suas possibilidades de execução, é a metodologia de ensino.

\section{METODOLOGIA DE ENSINO}

Escolhe-se uma metodologia construtivista de ensino para embasar a aplicação do material, normalmente é trabalhado uma das seguintes metodologias: “Aprendizagem Significativa”, "Metodologia da Problematização" ou "Instrução pelos Colegas". 
a. Aprendizagem Significativa - proposta por David Ausubel, caracteriza-se pela associação de um novo conceito a conhecimentos prévios dos indivíduos de forma a construir estruturas mentais que permitam assimilação do novo. Ou seja, o novo conhecimento para ser aprendido deve fazer algum sentido direto para a vida do aprendiz ou associar-se a outras ideias ou conceitos em sua mente.

Para facilitar este processo de aprendizagem 'Organizadores Prévios’, conteúdos introdutórios, devem ser utilizados, o material lúdico se configura como um ótimo organizador prévio, mas para ser eficaz, o aprendiz deve se identificar e se sentir motivado para utilizar esses materiais e fazer algum sentido direto para a sua vida ou associar-se a outras ideias ou conceitos em sua mente. Com esse interesse inicial o aprendiz se sente motivado a aprofundar-se no assunto (AUSUBEL, 1978).

b. Metodologia da Problematização - foi dividida em cinco etapas e parte da (1) observação da realidade vivida, identificação e escolha de problemas no processo de ensino-aprendizagem (2) processo de reflexão e definição dos pontos chave do problema observado; (3) teorização - busca por informações para embasar a resposta ao problema, (4) elaboração de hipóteses de solução e (5) realizar uma ação transformadora, ou seja, aplicação dos conhecimentos construídos na realidade vivida que serviu como ponto de partida (COLOMBO \& BERBEL, 2007; BERBEL, 2012).

c. Instrução pelos pares (Peer Instruction) - consiste em elaborar o material como apoio de modo que o aprendiz possa utilizá-lo antes da aula que irá abordar os conteúdos presentes no material elaborado. Na aula, o aluno responde a um questionário e o professor verifica os pontos menos assimilados e ministra a aula, promovendo debates entre pequenos grupos (de 3-4 alunos) que respondem novamente ao questionário ou parte dele. Desta forma, o professor consegue acompanhar a evolução do aprendizado e conduzir sua aula para dirimir as dúvidas que ainda restarem após as discussões em grupo (MAZUR, 2001).

Assim, sugere-se que para a aplicação/validação dos materiais produzidos e embasados em uma das metodologias de ensino descritas anteriormente seja utilizado o estudo de casos, que deve ser empregado a partir de uma comparação entre dois grupos - o que fez uso do material lúdico e um outro que não o utilizou. Essa comparação deve ser realizada com a finalidade de descobrir qual a contribuição do material aplicado para o aprendizado (FLICK, 2005).

\section{1 Coleta e análise de dados}

Para análise do impacto dessas atividades, junto ao público alvo, trabalhamos com a aplicação, antes e depois das intervenções, de questionários e/ou entrevistas de forma semiestruturada e/ou observação com os alunos. Além dos dados pessoais e do perfil socioeconômico são incluídas perguntas relativas aos conceitos abordados e satisfação em relação ao material testado (HILL\& HILL, 2005).

Antes de serem utilizados, os instrumentos de coleta de dados devem ser validados, ou seja, realizar um pré-teste ou estudo piloto com um pequeno número de pessoas do universo de sua pesquisa para avaliar a qualidade, clareza, validade, confiabilidade desses instrumentos e obter subsídios para melhorá-los.

Para a validação do material produzido, utiliza-se como método uma abordagem qualitativa, uma vez que ela se aplica ao estudo das relações, das representações, das percepções e das opiniões dos seres humanos (MINAYO, 2007).

Os métodos qualitativos têm sido utilizados prioritariamente em função de permitir compreender mais profundamente a percepção, crenças, atitudes, valores e motivação da realidade dos entrevistados/respondentes (GASKELL, 2002). 
Quando o LAMLEC realiza trabalhos com seus materiais produzidos, a partir do momento que escolhe sua metodologia de ensino, parte para a segunda fase, que é a escolha da metodologia de análise de dados. Sugere-se metodologias qualitativas para análise, algumas vezes apoiadas em dados numéricos, como por exemplo, a utilização de questionários com questões fechadas. As entrevistas são gravadas ou filmadas e depois transcritas, outra metodologia utilizada é a análise de imagens, principalmente quando solicitamos que os aprendizes descrevam suas percepções com desenhos. As análises são realizadas à luz de um dos seguintes referenciais teóricos:

a. Análise de Conteúdo

Segundo Bardin (1988) "é um conjunto de técnicas de análise de comunicações visando obter, por procedimentos sistemáticos e objetivos de descrição do conteúdo das mensagens, indicadores (quantitativos ou não) que permitam a inferência de conhecimentos relativos às condições de produção/recepção (variáveis inferidas) destas mensagens”. Nesse método realiza-se a sistematização a partir de: (a) uma pré-análise - organização do material e a formulação de hipóteses e tentativas de explicação dos textos/falas; (b) a exploração do material separação por categorias ou classificação por: temas, sentido das palavras, a construção de categorias orientam uma compreensão melhor; (c) tratamento dos resultados - a inferência e a interpretação e interpretação dos dados a partir da busca de significados mediante a interpretação além das palavras, ou seja, o significado por trás do apreendido. A análise de conteúdo possui variantes que inclui a determinação da frequência de ocorrência de determinadas palavras ou certas características de conteúdo.

\section{b. Análise de Discurso}

A análise de discurso é uma técnica interpretativa das falas dos sujeitos, levando-se em consideração a história dos indivíduos, o contexto da produção do discurso, o meio social e ideológico de poder no plano discursivo, buscando assim captar a essência do texto/fala dos entrevistados em seus conflitos, percepções, identidade e poder. Desta forma mescla elementos da linguística, psicanálise e ciências sociais. Analisa o que é dito e também o que é omitido no discurso (ORLANDI, 2005).

O dizer não é propriedade particular. As palavras não são somente daquele que as emite ou registra, elas têm significados pelo momento histórico, localidade e pela língua. As mesmas palavras são ditas e/ou escritas em diversas situações, o indivíduo não tem controle sobre a interpretação do que diz.

O precursor desta metodologia foi Michel Pêcheux influenciado pelo marxismo, que considera não haver discurso neutro, todos são baseados na ideologia de cada indivíduo, que mesmo sem ter clareza de sua ideologia, possui um discurso impregnado do seu meio sócio, cultural e econômico. Foulcaut, Althusser, Lacan e Bakhtin também contribuíram de forma significativa para o desenvolvimento desta metodologia (GREGOLIN, 2007).

\section{c. Discurso do Sujeito Coletivo}

Esta técnica possui um caminho sistemático e padronizado, na qual após a transcrição das entrevistas, realiza-se uma análise identificando as "Ideias Centrais" ou “Ancoragens", que são frases, expressões ou palavras que possuem significados semelhantes e a partir daí, cria-se um só discurso, constituído por partes das diversas falas/textos com sentido semelhante dos diversos entrevistados (LÈFEVRE, 2000).

\section{d. Análise de Imagens}

A imagem/desenho também se configura um meio de expressão, ou seja, um ato intencional de criação de signos e dessa forma passível de análise. O instrumento de coleta de dados nessa metodologia são os desenhos criados pelos participantes do estudo, motivados pela interpretação ou percepção do aprendiz de um conceito ou questão levantada a partir do material educativo utilizado. Também é um método de análise de materiais obtidos 
a partir de um levantamento de dados impressos ou de vídeos, como por exemplo, pinturas, fotografias, gravuras, cinema, televisão, dentre outros (SANTAELLA \& NOTH, 2008).

O Signo constitui a interpretação da representação de um objeto perceptível ou não (um sentimento, por exemplo), portanto, com esta metodologia, busca-se encontrar os sentidos das relações que são criadas entre aquele que produz a imagem, o que nela está representado e o como as pessoas, consumidoras finais, a percebem (PEIRCE, 2005).

\section{OS PRODUTOS DISSEMINÁVEIS.}

Ao longo desses anos foi produzido no LAMLEC vários materiais lúdicos para o ensino, dentre eles, histórias em quadrinhos, documentários, curta metragens, animações, jogos de tabuleiro, jogos de computador, músicas, vídeo clips, livros ilustrados, cartilhas e folhetos e metodologias para a aplicação de júris simulados, discussões e debates. A seguir será apresentado alguns desses materiais.

\section{1 Animação}

Os materiais criados, apesar de serem feitos para uma determinada faixa etária e um perfil sociocultural, podem ser aplicados a diferentes públicos. Como, por exemplo, a animação da figura 1, construído com base nos conhecimentos científicos sobre a interação de antibióticos com leite.

\section{Figura 1 - Cenas da animação}

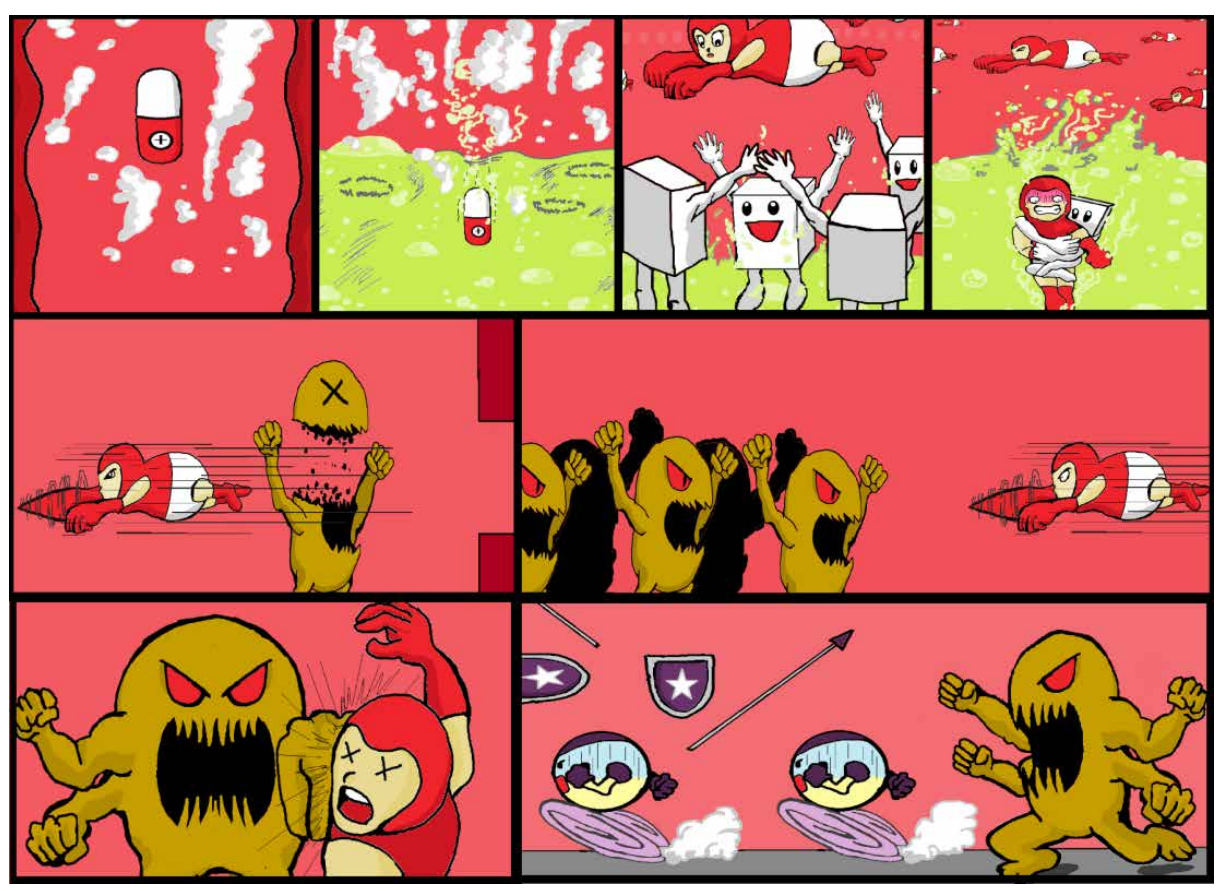

Fonte: dos autores.

A animação explica, de forma lúdica e científica, os malefícios de se tomar antibióticos com leite (uma forma de automedicação inadequada, incentivada por questões culturais e também pela falta do saber científico adequado). O material criado faz parte de um projeto que está em desenvolvimento (Nota 1). Inicialmente foi testado com 70 alunos (de 10 a 11 anos), do quinto ano do ensino fundamental e três professores de uma escola particular do município de Niterói - RJ. Numa fase preliminar, foram colhidos depoimentos dos participantes da pesquisa duas semanas após a aplicação do material. 
Observou-se que houve um grande interesse e assimilação dos conteúdos pelos participantes do estudo, além disso, os alunos foram multiplicadores para pais e familiares. Um dos alunos (sexo masculino, 10 anos de idade), em sua resposta, foi além do apresentado na animação, ele concluiu que não era somente na hora de tomar o antibiótico que não poderia ingerir o leite. Em seu discurso pontuou que sua mãe queria ministrar o medicamento com água, mas ele advertiu-a, dizendo que naquele momento, após o café da manhã, ele tinha acabado de beber leite e que o medicamento, apesar dele estar tomando com água, iria se encontrar com o leite no estômago, afinal seu café da manhã fora leite com chocolate. Assim, recomendou que ela deveria ter dado o medicamento uma hora antes dele beber o leite. Os alunos demonstraram gostar da animação (dos desenhos e do enredo da história). Os professores da escola em que se realizou o estudo relataram que a partir da animação iriam modificar suas práticas em relação ao uso de medicamentos com seus filhos e familiares. O mesmo material foi aplicado a turmas de graduação e pós-graduação do IFRJ, obtendo resultados e interesse pelo material semelhante aos outros públicos testados.

\section{2 Jogo de tabuleiro}

Outros materiais podem ser adaptados a conteúdos diversos. A exemplo disso cita-se um jogo de tabuleiro criado originalmente para abordar o uso racional de medicamentos, mas também utilizado para abordar assuntos ligados a: homeopatia, lixo e conservação ambiental, fitoterapia, dentre outros. Para isso, basta elaborar novas perguntas, dicas e respostas sobre o assunto a ser abordado.

O tabuleiro do jogo (figura2) representa um trecho de um bairro comercial, constituído por uma praça e quatro quadras ao redor, e funciona da seguinte forma: o jogador é representado por uma pessoa que caminha pelas ruas deste bairro; o jogador joga o dado e caminha o número de casas relativas ao número sorteado; na casa em que ele parar estará escrito DICA ou o nome de algum estabelecimento comercial; a carta DICA contém um texto que dará subsídios para que o participante possa responder algumas perguntas. As demais casas são correspondentes a cartas PERGUNTA, em que cada estabelecimento comercial corresponde a um tipo de pergunta. Dessa forma, na casa FARMÁCIA o jogador responderá sobre medicamentos, na casa SUPERMERCADO sobre nutrição, na casa MUSEU sobre a história da ciência, na casa CONSULTÓRIO sobre sintomas, na casa VETERINÁRIO sobre vetores de doenças e assim por diante, abordando temas sobre prevenção, tratamento, uso racional de medicamentos, dentre outros assuntos sobre a área de saúde e medicamentos.

Figura 2 - Tabuleiro do jogo educativo

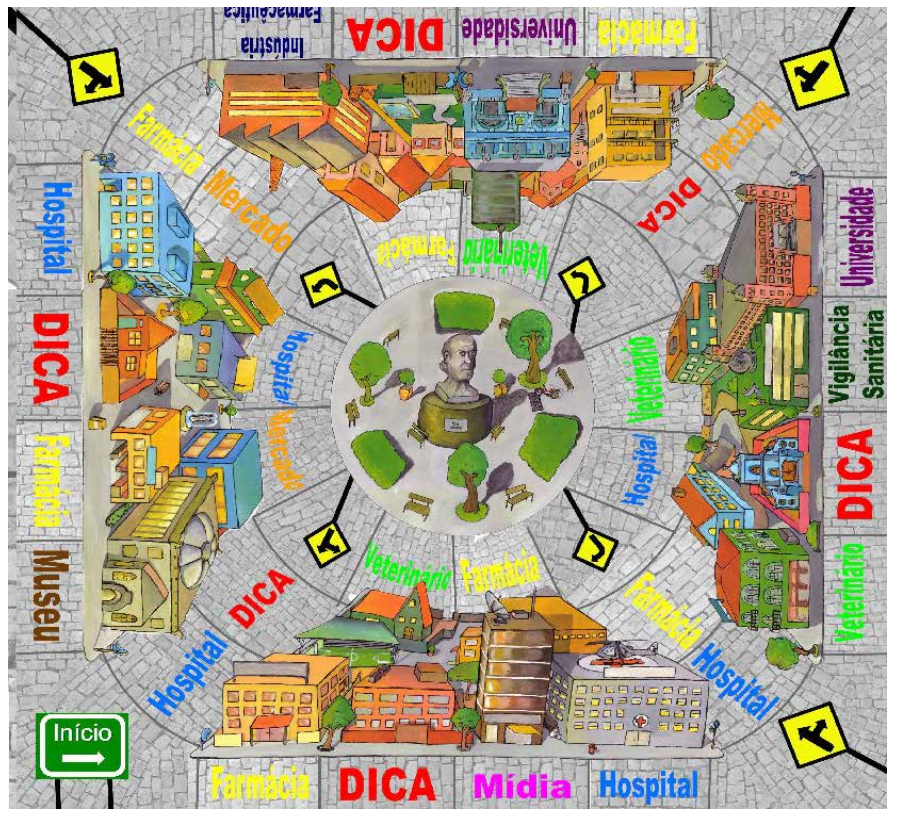

Fonte: dos autores. 


\section{3 História em quadrinhos (HQ)}

Objetivando seguir os passos da "aprendizagem significativa” foi realizada uma análise dos conteúdos sobre medicamentos em livros didáticos de Biologia do Ensino Médio. Foi identificado o conhecimento prévio de alunos e professores sobre o uso de medicamentos e finalmente construído uma história em quadrinhos (figura 3) e um texto.

A história em quadrinhos foi baseada em fatos reais, sobre a automedicação no caso de intoxicação alimentar. É narrada da seguinte forma: Um jovem, durante uma viagem com amigos começa a sentir sintomas comuns, como uma indisposição acompanhada de dores abdominais, diarreia e até mesmo vômito. Ele indaga, como frequentemente falamos, "Não é nada demais, deve ter sido alguma coisa que eu comi”. O jovem acaba por se automedicar, tendo o seu problema agravado e somente vai ao médico quando não têm mais condições físicas para continuar o seu passeio.

Junto à história em quadrinhos foi apresentado para os alunos do Ensino Médio e Graduação, de acordo com o artigo Corrêa et al. (2016), um texto abordando o mesmo tema, mais aprofundado e com tópicos adicionais. O objetivo era que os alunos pudessem fazer uma conexão entre o uso inadequado de medicamentos e as recomendações médicas (contidos na HQ), além de uma descrição mais detalhada dos problemas inerentes a automedicação e a intoxicação alimentar.

\section{Figura 3 - Última página da história em quadrinhos}

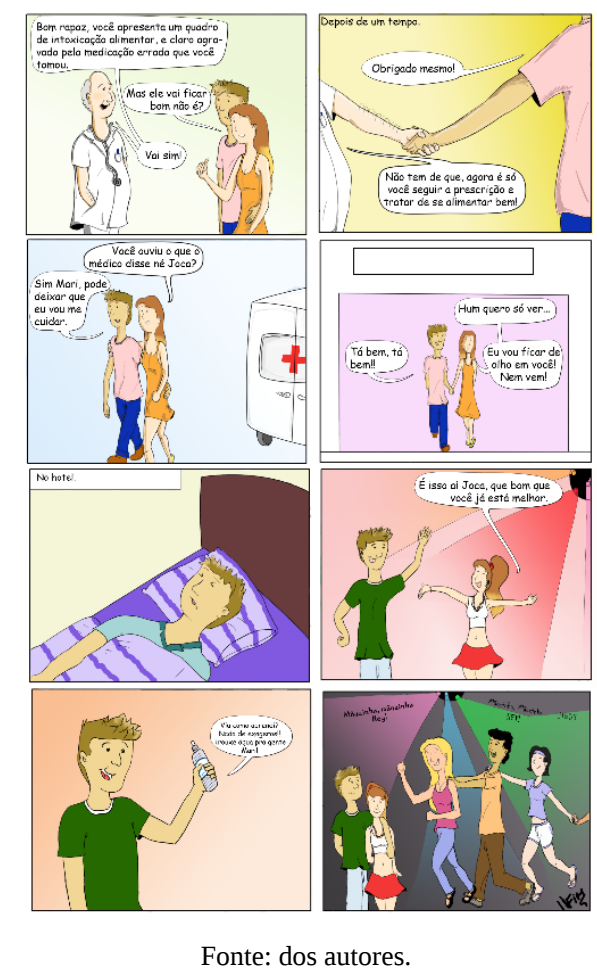

Pode-se citar aqui alguns dos resultados encontrados com esse trabalho: 1 - que os livros didáticos analisados, no que diz respeito ao conteúdo sobre medicamentos, necessitam ser adequados à abordar o Uso Racional de Medicamentos, para que dessa forma possam atender as recomendações dos Parâmetros Curriculares Nacionais; 2 - os habitus criados no convívio familiar em relação ao uso e representações sociais de medicamentos são transmitidos de geração a geração e, desta forma, é perpetuado o uso inadequado de medicamentos e 3 - a HQ elaborada contribuiu para o aprendizado dos estudantes sobre os riscos da automedicação, pois serviu como um organizador prévio dos conhecimentos dos alunos, que se identificaram com o enredo da história e quiseram se aprofundar mais no assunto 
com um texto que lhes foi apresentado. Observamos também que houve um sinergismo entre os conhecimentos dos alunos que utilizaram a história em quadrinhos e o texto, ou seja, o conhecimento construído por este grupo foi maior que a soma dos conhecimentos dos dois grupos que tiveram acesso a somente um dos materiais. Dessa forma, para esse exemplo, os resultados sugerem que o ensino de ciências e a divulgação científica sobre o tema com materiais didáticos lúdicos podem contribuir para a apropriação de práticas saudáveis em relação ao uso de medicamentos.

Este trabalho foi agraciado com a primeira colocação do Prêmio Nacional de Incentivo à Promoção do Uso Racional de Medicamentos “LENITA WANNMACHER”, premiação do Ministério da Saúde.

\section{4 Músicas}

Músicas possuem um grande potencial para a utilização como auxiliar no ensino de ciências, pois a música é um elemento extremamente presente no cotidiano da grande maioria dos indivíduos.

A música com a intenção de transmitir conteúdos e informações é muito antiga, as igrejas há muitos séculos utilizam a música como um modo de convencimento e catequização, os povos indígenas e escravos africanos as usavam para passarem mensagens, as cantigas possuíam em suas letras conteúdos com finalidades "educativas" do ponto de vista da época em que foram criados (muitas vezes uma educação do amedrontamento), outros exemplos da atualidade também com a intenção de transmitir informação são os dingols feitos para candidaturas políticas, propagandas de venda de produtos ou para a consolidação de uma marca (GRANJA, 2010).

Foi elaborado pelo LAMLEC uma série de músicas (exemplo de letra musical no prefácio desse artigo) com temas ligados à saúde e aplicadas à algumas turmas, como por exemplo, turmas da disciplina de Fitoterapia de um curso de graduação do IFRJ. A maioria das músicas eram paródias de músicas conhecidas, com os mais diversos ritmos musicais, outra tiveram composição própria.

Na mesma disciplina citada acima, a cada aula, uma nova música era apresentada. Observou-se os rendimentos desses alunos em uma avaliação da referida disciplina. Nela havia questões, que abordavam conteúdos com o mesmo nível de dificuldade, com tópicos que eram tratados nas músicas e outros somente ministrados em aulas expositivas. Como resultado preliminar, obteve-se no rendimento dos alunos nas questões relacionadas aos conteúdos apresentados nas músicas um total de 83\% de acertos, em contrapartida, 50\% de acertos para os assuntos somente abordados nas aulas expositivas. Este fato deixou a todos os integrantes do laboratório otimistas em ampliarem a divulgação e os trabalhos realizados com as músicas, além de servirem como estímulo na criação de clipes, que já está acontecendo, para serem associados à essas letras e melodias.

\section{5}

\section{BREVES CONSIDERAÇÕES}

O LAMLEC é um espaço de formação de indivíduos na área de criação e utilização de materiais lúdicos para o ensino de ciências e divulgação científica. A diversidade de seus integrantes, alunos de ensino médio/técnico, graduandos em Produção Cultural, Licenciatura em Física, Química e Matemática, Bacharel em Química, Gestão da Produção e graduados em Pedagogia, Química, Biologia, Farmácia, História, entre outros, favorece uma riqueza nas trocas cultural e profissional. Além desses diferentes tipos de formação, a atuação dos integrantes do LAMLEC acontece por diversas formas, de acordo com seus níveis de comprometimento que são desde professores orientadores, alunos de Mestrado em Ensino de Ciências, bolsistas de projetos de pesquisa do nível técnico e graduação, monitores, voluntários, curiosos e simpatizantes.

Os produtos do LAMLEC são criados, na maior parte das vezes, para atender a demanda das disciplinas e projetos de pesquisa dos docentes pertencentes ao laboratório. No início os materiais foram pensados para a graduação e ensino médio, no decorrer do tempo observou-se que esses mesmos materiais poderiam ser usados também para outros públicos. A divulgação e distribuição desses produtos dissemináveis ocorre somente após 
a validação, aplicação e testes que buscam entender a contribuição desses produtos. A aplicação e análise dos resultados obtidos é realizada pela escolha de uma metodologia que se afine mais ao público alvo, ao tipo de material e ao tema proposto, como explicitado ao longo do texto. Estes são trabalhos que se esforçam por contemplar a diversidade cultural tanto no material didático criado, como na composição do próprio grupo criador. Há o sentimento de pertencimento ao grupo pela criação coletiva.

Nós, integrantes do LAMLEC acreditamos que essa heterogeneidade vivenciada num espaço fora da sala de aula, situado dentro de um espaço de educação formal, pode ser muito rica para iniciativas que reúnem a Divulgação Científica, o Lúdico, e o Ensino de Ciências. Este é um caminho que busca tornar o Ensino de Ciências cada vez mais atrativo e representativo de um mundo globalizado e conectado à uma gama de informações. Os aprendizes devem se sentir familiarizados dentro desse processo. Desta forma, precisamos falar o mesmo linguajar e usar das tecnologias presentes no cotidiano desses alunos, sem perdermos o objetivo, que deve ser pautado nessas novas metodologias de ensino, com o acompanhamento de uma apurada análise em todo o percurso.

\section{NOTAS}

\section{1 Aspectos éticos}

Os trabalhos apresentados neste artigo fazem parte de um projeto que foi aprovado pelo Comitê de Ética em Pesquisas do IFRJ e está protocolado sob o no 0004.0.406.000-08 CAAE/SISNEP - Sistema Nacional de Informação sobre Ética em Pesquisa envolvendo Seres Humanos. 


\section{REFERÊNCIAS}

ARAÚJO-JORGE, Tânica C. de .(org.). Ciência e Arte: encontros e sintonias. Rio de Janeiro: Ed. Senac Rio, 2004.

AUSUBEL, D. P. ; NOVAK, J. D. e HANESIAN, H. Psicologia educacional. Rio de Janeiro: Interamericana, 1978. 625p.

BARDIN, L. Análise de conteúdo. Lisboa: Edições 70, 1988. 226 p.

BERBEL, N. A. N. A metodologia da problematização com o arco de Maguerez: uma reflexão teóricoepistemológica. Londrina: EDUEL, 2012.

SANTOS, B. S. dos. Um discurso sobre as ciências. Porto: Afrontamento, 1987.

BRASIL. MINISTÉRIO DA EDUCAÇÃO E CULTURA. Lei de Diretrizes e Bases da Educação Nacional. Lei $\mathrm{n}^{\circ}$ 9.394, de 20 de dezembro, 1996.

BRASIL, MINISTÉRIO DA EDUCAÇÃO E CULTURA. Secretaria de Educação Fundamental. Parâmetros Curriculares nacionais. Brasília: 1997.

BRASIL. MINISTÉRIO DA EDUCAÇÃO E CULTURA. Centenário da Rede Federal de Educação Profissional e Tecnológica. 2009. Disponível na Internet: < http://portal.mec.gov.br/setec/arquivos/centenario/ historico_educacao_profissional.pdf $>$. Acesso em: 05 jul.2015.

BRASIL. MINISTÉRIO DA EDUCAÇÃO E CULTURA. Lei no 9394, de 20/12/1996. Estabelece as Diretrizes e Bases para a Educação Nacional. Disponível na Internet: <http://portal.mec.gov.br/seed/arquivos/pdf/tvescola/ leis/lein9394.pdf>. Acesso em: 5 jul. 2015.

BRASIL. Presidência da República. Casa Civil (Subchefia para Assuntos Jurídicos). Lei nº 452 de 05/07/1937. Organiza a Universidade do Brasil. Disponível na Internet: < http://www.planalto.gov.br/ccivil_03/Leis/1930-

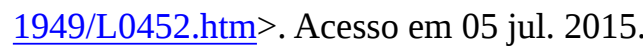

BRASIL. Senado Federal. Secretaria de Informação Legislativa. Decreto-Lei n.1063, de 20/01/1939. Dispõe sobre a transferência de estabelecimentos de ensino da Universidade do Distrito Federal para a Universidade do Brasil. Disponível na Internet: < $\underline{\text { http://legis.senado.leg.br/legislacao/ListaPublicacoes. }}$ action?id=7940\&tipoDocumento=DEL\&tipoTexto=PUB> . Acesso em 5 jul. 2015.

CACHAPUZ, GIL-PEREZ, CARVALHO, JOÃO PRAIA e VILCHES. A Necessária Renovação do Ensino das Ciências. Ed, Zara Hoffmann, 2005.

CARVALHO, A. M. P., DE E GIL-PÉREZ, D. Formação de professores de ciências - tendências e inovações, 10.ed. São Paulo: Editora Cortez, 2011 (Coleção Questões da nossa época; v. 28).

CIAVATTA, M. A cultura material escolar em trabalho e educação. A memória fotográfica de sua transformação. Educação e Filosofia. Uberlândia, v.23, n.46, p.32-72, jul/dez. 2009.

COLLEY, H.; HODKINSON, P. \& MALCOLM, J. “Non-formal learning: mappingthe conceptual terrain”. A consultation report, Leeds: University of Leeds Lifelong Learning Institute. 2002. Disponível em: $<$ http:// www.infed.org/archives/e-texts/colley_informal_learning.htm>. Acesso em 5 jul. 2015.

COLOMBO, A. A.; BERBEL, N. A. N. A Metodologia da Problematização com o Arco de Maguerez e sua relação com os saberes de professores. Semina: Ciências Sociais e Humanas, Londrina, v. 28, n. 2, p. 121-146, 2007. 
CORRÊA, A. D.; RÔÇAS, G. ; LOPES, R. M. ; ALVES, L. A. A utilização de uma história em quadrinhos como estratégia de ensino sobre o Uso Racional de Medicamentos. Alexandria (UFSC), v. 9, p. 83-102, 2016.

CRUZ, G. C. A contribuição do lúdico na aprendizagem significativa em História - XXVII Simpósio Nacional de História, Natal - 2013.

DELIZOICOV, D.; ANGOTTI, J. A.; PERNAMBUCO, M. M.; DA SILVA, A. F. G. Ensino de Ciências: fundamentos e métodos. São Paulo: Cortez Editora. 2002. 364 p.

FÁVERO, M. L de A. A Universidade no Brasil: das origens à reforma universitária de 1968. Educar. Curitiba, n.28, p.17-36, 2006. Ed. UFPR.

FAZENDA, Ivani C. Arantes. Integração e Interdisciplinaridade no Ensino Brasileiro: Efetividade ou Ideologia. 6. ed.: São Paulo: Edições Loyola, 2011.

FREIRE, P. Pedagogia da Autonomia: saberes necessários à prática educativa. Editora: Paz e Terra, 1996.

Flick, U. Métodos Qualitativos na Investigação Científica. Lisboa: Monitor, 2005. 305p.

GASKELL, G. (2002). Entrevistas individuais e grupais. In: M. W. Bauer, \& G. Gaskell (Orgs.), Pesquisa qualitativa com texto, imagem e som: um manual prático (pp.64-89). Petrópolis: Vozes.

GOHM, M. G. Educação não-formal e cultura política. Impactos sobre o associativismo do terceiro setor. São Paulo, Cortez. 1999.

GRANJA, Carlos Eduardo de Souza Campos. Musicalizando a escola: música, conhecimento e educação. SP: Escrituras Editora, 2010.

GREGOLIN, M. R. V. Análise do discurso e mídia: a (re)produção de identidades. Comunicação, Mídia e Consumo. São Paulo: vol. 3, n. 11, p. 11-25, 2007.

Hill, M.; Hill, A. Investigação por questionário. 6. ed. Lisboa: Edições Silabo, 2005. 377p.

HOBSBAWN, E. A Era de Ouro. IN: Era dos Extremos: o breve século XX, 1914-1991. São Paulo:

Companhia das Letras, 1995, p.223-363.

JAPIASSU, Hilton. Interdisciplinaridade e Patologia do Saber. Rio de Janeiro: Imago, 1976.

KRASILCHIK, M. Prática de ensino de biologia. 4. ed. São Paulo: Edusp, 2004.

LEFÈVRE F, LEFÈVRE AMC. O discurso do sujeito coletivo - Um novo enfoque em pesquisa qualitativa (Desdobramentos). Caxias do Sul, RS: EDUCS; 2000.

LIBÂNEO, J. C. Pedagogia e Pedagogos, para quê. São Paulo, Cortez, 2005.

MARTINS, I. NASCIMENTO, T. G., ABREU, T. B. Clonagem na sala de aula. Um exemplo do uso didáticode um texto de divulgação científica. Investigações em Ensino de Ciências. Rio Grande do Sul, v. 9, n. 1, 2004.

MAZUR, E. Peer Instruction: A User’s Manual (Prentice Hall, New York, 2001).

MINAYO, M. C. S. O desafio do conhecimento. Pesquisa qualitativa em saúde. São Paulo: HUCITEC, 2007

MOREIRA, M. A. Aprendizagem Significativa. Brasília; Ed. da UNB, 1999.

MORIN, E. Os sete saberes necessários à educação do futuro. São Paulo: Cortez. 2000. 
ORLANDI, E. P. Análise do Discurso: princípios \& procedimentos. 6. ed. São Paulo: Pontes, 2005.

PEIRCE, Charles S. Semiótica. Tradução de José Teixeira Coelho Neto. 3. ed. 2. reimp. de 2000. São Paulo: Perspectiva, 2005.

PERRENOUD, P. Avaliação da excelência: a regulação das aprendizagens entre duas lógicas. Porto Alegre: ArtMéd, 1999.

PICANÇO, I. S. (coord.). Gênese do Ensino Técnico Industrial no Brasil. Instituto Nacional de Pesquisas Educacionais Anísio Teixeira (INEP), 1995. Disponível em: < http://portal.mec.gov.br/setec/arquivos/pdf2/ artigos_genese.pdf>. Acesso em: 5 jul. 2015.

PINTO, Gisnaldo Amorim. Divulgação Científica como literatura e o ensino de ciências. Tese de Doutorado da Faculdade de Educação da Universidade de São Paulo, 2007.

SANTAELLA, Lúcia; NÖTH, Winfried. Imagem: cognição, semiótica, mídia. 1. ed. 5. reimp. São Paulo: Iluminuras, 2008. 222 p.

SILVEIRA, A. F.; ATAIIDE, A. R. P.; FREIRE, M. L. F. Atividades lúdicas no ensino de ciências: uma adaptação metodológica através do teatro para comunicar a ciência a todos. Educar, Curitiba, n. 34, p. 251-262, 2009. Editora UFPR.

SOUSA, E. M., SILVA, F. O.; SILVA, T. R. S.; SILVA, P. H. G. A importância das atividades lúdicas: uma proposta para o ensino de Ciências. VII CONNEPI 2012.

UNESCO. Educação: Um Tesouro a Descobrir. MEC, Cortez Editora, São Paulo, 1999.

ZIBAS, D. M. L. Uma visão geral do Ensino Técnico no Brasil. A legislação, as críticas, os impasses e os avanços. Fundação Carlos Chagas. Texto apresentado no: Encuentro Internacional sobre Educación Técnico-Profesional, financiado pelo BID - Banco Interamericano de Desenvolvimento e organizado pelo BID e pelo Ministerio de Educación, Ciencia y Tecnología de la Nación Argentina. Buenos Aires, em 6 e 7 de dezembro de 2006. 